\title{
Detection of Virulence to Resistance Gene Sr36 Within the TTKS Race Lineage of Puccinia graminis f. sp. tritici
}

\author{
Y. Jin and L. J. Szabo, United States Department of Agriculture-Agricultural Research Service, Cereal Disease \\ Laboratory, University of Minnesota, St. Paul 55108; M. N. Rouse, Department of Plant Pathology, University of \\ Minnesota, St. Paul 55108; T. Fetch, Jr., Cereal Research Centre, Agriculture and Agri-Food Canada, Winnipeg, \\ MB, R3T 2M9, Canada; Z. A. Pretorius, Department of Plant Sciences, University of the Free State, Bloemfontein \\ 9300, South Africa; and R. Wanyera and P. Njau, Kenyan Agricultural Research Institute, National Plant Breeding \\ Research Center, P.O. Njoro, Kenya
}

\begin{abstract}
Jin, Y., Szabo, L. J., Rouse, M. N., Fetch, T., Jr., Pretorius, Z. A., Wanyera, R., and Njau, P. 2009. Detection of virulence to resistance gene Sr36 within the TTKS race lineage of Puccinia graminis f. sp. tritici. Plant Dis. 93:367-370.

The stem rust resistance gene $\operatorname{Sr} 36$ confers a near-immune resistance reaction to many races of Puccinia graminis f. sp. tritici and is highly effective against race TTKSK (syn. Ug99), which possesses unusually broad virulence combinations. Because this gene is widely used in United States soft winter wheat germplasm and cultivars, it has been considered to be an important source of resistance to TTKSK. In 2007, moderately susceptible infection responses were observed on wheat lines and cultivars carrying $\mathrm{Sr} 36$ in a field screening nursery for stem rust at Njoro, Kenya. We derived 18 single-pustule isolates from stem rust samples collected from the 2007 Njoro nursery. The isolates were evaluated for virulence on 20 North American stem rust differential lines and on wheat lines and cultivars carrying $\mathrm{Sr} 36, \mathrm{Sr} 31+\operatorname{Sr} 36$, and $\mathrm{Sr} 24+\operatorname{Sr} 31$. Of the 18 isolates, 10 produced infection types $3+$ to 4 on line W2691SrTt-1 (monogenic for Sr36) and other lines that carry $\operatorname{Sr} 36$ and belonged to a new virulence phenotype that was not detected in previous years. These isolates were identified as race TTTSK. The remaining eight isolates were identified as races TTKSK (five isolates) and TTKST (three isolates), with avirulence and virulence, respectively, to $\operatorname{Sr} 24$. Thirteen simple sequence repeat (SSR) markers were used to examine the genetic relationships among the three races in the TTKS lineage. All isolates in the lineage shared an identical SSR genotype and were clearly different from North American races. In all, 16 wheat cultivars and 60 elite breeding lines, postulated to possess Sr36, were susceptible to race TTTSK. The occurrence of race TTTSK with combined virulence on Sr31 and Sr36 has further broadened the virulence spectrum of the TTKS lineage and rendered an important source of resistance ineffective.
\end{abstract}

Wheat stem rust resistance gene Sr36 (syn. SrTt-1), derived from Triticum timopheevii (1), exhibits a near-immune reaction to races TTKSK and TTKST of Puc-

Corresponding author: Y. Jin

E-mail: yuejin@umn.edu

Mention of a trademark, vendor, or proprietary product does not constitute a guarantee or warranty of the product by the United States Department of Agriculture and does not imply its approval to the exclusion of other product or vendors that also may be suitable.

The United States Department of AgricultureAgricultural Research Service Cereal Disease Laboratory maintains seed stocks used in this study, and they are available upon request from the corresponding author.

Accepted for publication 10 December 2008.

doi:10.1094/PDIS-93-4-0367

This article is in the public domain and not copyrightable. It may be freely reprinted with customary crediting of the source. The American Phytopathological Society, 2009. cinia graminis f. sp. tritici at both the seedling and adult plant stages $(3,5)$. The gene is commonly found in the U.S. soft winter wheat germplasm (4). Although races of $P$. graminis f. $\mathrm{sp}$. tritici virulent to Sr36 are common, this gene has been considered a valuable source of stem rust resistance because it is highly effective against Ug99 and widely present in adapted germplasm. In a 2007 stem rust nursery in Njoro, Kenya, we observed scattered moderately susceptible uredinia occurring on lines carrying $\operatorname{Sr} 36$. These included lines monogenic for Sr36 (W2691SrTt-1 and CI12632/8*LMPG), cvs. Enkoy and Cook, and a number of breeding lines suspected to carry Sr36, indicating the likely presence of Sr36 virulence in the nursery. The objectives of this study were to determine the race identity of stem rust isolates that produced moderately susceptible infection responses on lines carrying $\operatorname{Sr} 36$ and to determine their genetic relationship with races TTKSK and TTKST that were predominant in previous Njoro stem rust nurseries.

\section{MATERIALS AND METHODS}

Eleven samples were collected in May and October 2007 from wheat lines and cultivars known or suspected to carry $\mathrm{Sr} 24$, $S r 31$, or $S r 36$ in a stem rust nursery planted in Njoro, Kenya. Methods for sample collection, deriving single-pustule isolates, inoculation of differentials, and disease assessment were as described previously (3). The North American race nomenclature system $(6,7)$, modified recently to further delineate races in the TTKS lineage (3), was used. This modification enlarged the differential set from 16 to 20 lines to include four monogenic lines carrying $\operatorname{Sr} 24, \operatorname{Sr} 31, \operatorname{Sr} 38$, and $\operatorname{SrMcN}$. Selected isolates and check isolates were also tested on the supplemental lines Siouxland (PI 483469, carrying Sr24+Sr31), CI12632/8*LMPG (monogenic line for Sr36), Roughrider (CI 17439, carrying Sr36), Enkoy (an Ethiopian cultivar carrying Sr36), Sisson (PI 617053, carrying Sr31+Sr36), and Triumph 64 (CI 13679, donor of SrTmp for the differential line CnsSrTmp) (Table 1). Each single-pustule isolate was evaluated two to three times on the differential set and supplemental lines. Selected wheat cultivars postulated to possess $\operatorname{Sr} 36$ in previous studies $(4,10)$ and entries of the 2007 soft red winter wheat regional nurseries were tested against an isolate with $\mathrm{Sr} 36$ virulence and against races TTKSK and TTKST that are avirulent to $S r 36$.

Determination of simple sequence repeat genotypes. DNA was extracted from urediniospores using an OmniPrep DNA extraction kit (GenoTech, St. Louis) as described by Anikster et al. (2). Polymerase chain reaction (PCR) amplification conditions of simple sequence repeat (SSR) loci and detection of alleles were as described previously (9). SSR markers used are shown in Table 2. Seventeen isolates were used in the SSR analysis, which included the three checks (Table 1), nine isolates of race TTTSK (Table 1 except 07KEN51-4), and five standard North American isolates (56ND9, race MCCF; 60ND55C, race RCRS; 70NE286-2, race TMLK; 76MN1391, race HFLG; and $79 \mathrm{MEX} 10 \mathrm{~B}$, race MCCD). 


\section{RESULTS AND DISCUSSION}

In total, 18 single-pustule-derived isolates of $P$. graminis f. sp. tritici from the 2007 Njoro collections were used in this study. Infection types (ITs) on selected differential lines and supplemental lines are presented in Table 1 . ITs 0 to $2+$ were considered low (isolate avirulent and host line resistant) and ITs 3 to 4 were considered high (isolate virulent and host line susceptible). All isolates from the 2007 samples produced a high IT on Benno Sr31/6*LMPG (monogenic for $S r 31$ ) and, thus, belong to the TTKS lineage. When tested on the 20 differential lines, isolates were differentiated into three races. Five isolates (07KEN04-1, 07KEN04-2, 07KEN11-2, 07KEN52-4, and 07KEN603) produced ITs similar to that of the check isolates, Ug98-1-1 and 04KEN156/04, and were identified as race TTKSK. These

Table 1. Infection types produced on selected differential and supplemental lines by isolates of the TTKS lineage of Puccinia graminis $\mathrm{f}$. sp. tritici ${ }^{\mathrm{w}}$

\begin{tabular}{|c|c|c|c|c|c|c|c|c|c|c|c|}
\hline Isolate $^{x}$ & $\begin{array}{l}\text { W2691 } \\
\text { SrTt-1 } \\
(\text { Sr36) }\end{array}$ & $\begin{array}{c}\text { LcSr24Ag } \\
(\operatorname{Sr} 24)\end{array}$ & $\begin{array}{c}\text { Benno } \\
\text { Sr31/6* } \\
\text { LMPG }(\text { Sr31) }\end{array}$ & $\begin{array}{l}\text { Siouxland } \\
\text { (Sr24+ } \\
\text { Sr31) }\end{array}$ & $\begin{array}{l}\text { CI12632/8* } \\
\text { LMPG } \\
\text { (Sr36) }\end{array}$ & $\begin{array}{l}\text { Roughrider } \\
\quad(\text { Sr36) }\end{array}$ & $\begin{array}{l}\text { Enkoy } \\
(\mathrm{Sr36})\end{array}$ & $\begin{array}{c}\text { Sisson } \\
(\mathrm{Sr31+} \\
\text { Sr36) }\end{array}$ & $\begin{array}{c}\text { Triumph } 64 \\
(\text { SrTmp })\end{array}$ & $\begin{array}{c}\text { Cns_T_mo } \\
\text { no_deriv } \\
(\text { Sr } 21)\end{array}$ & Race $^{y}$ \\
\hline Ug98-1-1 & 0 & 2 & 4 & $2-$ & 0 & 0 & 0 & 0 & 2 & 4 & TTKSK \\
\hline 04KEN156/04 & 0 & 2 & 4 & 2 & 0 & 0 & 0 & 0 & 2 & 4 & TTKSK \\
\hline 06KEN19v3 & 0 & 3 & 4 & 3 & 0 & 0 & 0 & 0 & 2 & $3+$ & TTKST \\
\hline 07KEN04-1 & 0 & 2 & $3+$ & 2 & 0 & 0 & 0 & 0 & 2 & 4 & TTKSK \\
\hline 07KEN04-2 & 0 & 2 & $3+$ & 2 & 0 & 0 & 0 & 0 & 2 & $3+$ & TTKSK \\
\hline 07KEN11-2 & 0 & $2-$ & $3+$ & $2-$ & 0 & 0 & 0 & 0 & 2 & 4 & TTKSK \\
\hline 07KEN52-4 & 0 & 2 & $3+$ & 2 & 0 & 0 & 0 & 0 & $2+$ & 3 & TTKSK \\
\hline 07KEN60-3 & 0 & 2 & 4 & 2 & 0 & 0 & 0 & 0 & 2 & 4 & TTKSK \\
\hline 07KEN11-1 & 0 & 3 & $3+$ & 3 & 0 & 0 & 0 & 0 & $2+$ & 4 & TTKST \\
\hline 07KEN18 & 0 & $3+$ & $3+$ & 3 & 0 & 0 & 0 & 0 & 2 & $3+$ & TTKST \\
\hline 07KEN25 & 0 & 3 & 4 & 3 & 0 & 0 & 0 & 0 & 2 & $3+$ & TTKST \\
\hline 07KEN24-1 & 4 & 2 & 4 & 2 & 4 & $2+3-$ & 3 & 3 & $2+$ & $3+$ & TTTSK \\
\hline 07KEN24-2 & 4 & 2 & 4 & 2 & 4 & $3+$ & 4 & 4 & 2 & $3+$ & TTTSK \\
\hline 07KEN24-4 & 4 & 2 & 4 & $2-$ & 4 & $2+3-$ & 3 & 4 & 2 & $3+$ & TTTSK \\
\hline 07KEN51-4 ${ }^{\mathrm{Z}}$ & $3+$ & 2 & 4 & 2 & 3 & $3-$ & 3 & 3 & 2 & $3-$ & TTTSK \\
\hline 07KEN52-1 & 4 & 2 & 4 & $2-$ & 4 & $2++$ & $3+$ & 4 & 2 & $3-$ & TTTSK \\
\hline 07KEN52-3 & 4 & 2 & 4 & 2 & 4 & $2+3-$ & 4 & $3+$ & $2+$ & 3 & TTTSK \\
\hline 07KEN55-1 & 4 & 2 & 4 & 2 & 4 & 3 & 4 & $3+$ & 2 & $3+$ & TTTSK \\
\hline 07KEN56-2 & 4 & 2 & $3+$ & 2 & 4 & 3 & $3+$ & $3+$ & $2+$ & $2+3-$ & TTTSK \\
\hline 07KEN24-3 & 4 & 2 & $3+$ & $\ldots$ & $\ldots$ & $\ldots$ & $\ldots$ & $\ldots$ & $\ldots$ & $3+$ & TTTSK \\
\hline 07KEN57-4 & 4 & 2 & 4 & $\ldots$ & $\ldots$ & $\ldots$ & $\ldots$ & $\ldots$ & $\ldots$ & 3 & TTTSK \\
\hline
\end{tabular}

${ }^{\mathrm{w}}$ Infection types (ITs) at the seedling stage following the descriptions of Stakman et al. (8), where IT $0, ;, 1,2$ or combinations thereof were considered low infection types and ITs 3 to 4 were considered high infection types. Plus (+) and minus (-) signs were used to denote slightly larger or smaller pustules, respectively, deviated from the defined type; ... indicates not tested on the supplemental differential lines.

x Isolates Ug98-1-1 and 04KEN156/04 are check-isolates for race TTKSK and 06KEN19v3 is a check-isolate for race TTKST. The remaining isolates are derived from the 2007 Njoro collections.

y Races of $P$. graminis f. sp. tritici.

${ }^{\mathrm{z}}$ Not included in the simple sequence repeat genotype analysis.

Table 2. Comparison of simple sequence repeat (SSR) genotypes of selected Puccinia graminis f. sp. tritici races

\begin{tabular}{|c|c|c|c|c|c|c|}
\hline \multirow[b]{2}{*}{ SSR $^{y}$} & \multirow[b]{2}{*}{ No. of alleles } & \multicolumn{4}{|c|}{ Genotypes } & \multirow[b]{2}{*}{ Primers } \\
\hline & & TTKSK & TTSKT & TTTSK & N. Am. ${ }^{\mathrm{z}}$ & \\
\hline \multirow[t]{2}{*}{ PgtSSR3 } & 4 & A & A & A & $\mathrm{B}, \mathrm{C}, \mathrm{D}$ & PgtSSR3F: GGACCAAAACCAGAACCAGA \\
\hline & & & & & & PgtSSR3R: CCCACTCCTAATCCTCACGA \\
\hline \multirow[t]{2}{*}{ PgtSSR4 } & 2 & $\mathrm{C}$ & $\mathrm{C}$ & $\mathrm{C}$ & A, B & PgtSSR4F: CCAAGAGCGGCTAACAAAAG \\
\hline & & & & & $\ldots$ & PgtSSR4R: CAAACCAATCTTGCCGAAAT \\
\hline \multirow{2}{*}{ PgtSSR6 } & 5 & $\mathrm{D}$ & $\mathrm{D}$ & $\mathrm{D}$ & $\mathrm{A}, \mathrm{B}, \mathrm{C}$ & PgtSSR6F: CCAGCCAAGGAATGGTTAGA \\
\hline & & & & & & PgtSSR6R: AATGCCACTACCCAACTTCG \\
\hline \multirow[t]{2}{*}{ PgtSSR11 } & 4 & $\mathrm{C}$ & $\mathrm{C}$ & $\mathrm{C}$ & A, B & PgtSSR11F: AGTTCGGCATAGGGAATCCT \\
\hline & $\ldots$ & & & & $\ldots$ & PgtSSR11R: GATTTGCTGGCTTCGGTTAG \\
\hline \multirow[t]{2}{*}{ PgtSSR12 } & 4 & B & B & B & $\mathrm{A}, \mathrm{C}, \mathrm{D}$ & PgtSSR12F: CGACTACTTCATCAGCATTACCA \\
\hline & $\ldots$ & $\ldots$ & $\ldots$ & $\ldots$ & $\ldots$ & PgtSSR12R: TTCCTCTGTTTTCTCTCTCTCTCTC \\
\hline \multirow[t]{2}{*}{ PgtSSR14 } & 4 & A & A & A & $\mathrm{B}, \mathrm{C}$ & PgtSSR14F: TTCCACATTTCGAACAACGA \\
\hline & & & & & & PgtSSR14R: GCTTGTGTCCCAAGAGCTTC \\
\hline \multirow[t]{2}{*}{ PgtSSR20 } & 4 & A & A & A & $\mathrm{B}, \mathrm{C}$ & PgtSSR20F: CTAGATGAGGGGCAGCGAAT \\
\hline & & & & & & PgtSSR20R: TTCTCTCTCCTTCATCCTAACAACA \\
\hline \multirow[t]{2}{*}{ PgtSSR47 } & 4 & B & B & B & A, C, D & PgtSSR47F: GACTACTGGTGGCGGTCCT \\
\hline & & & & & & PgtSSR47R: AATCAGGTTGACCAGGATGG \\
\hline \multirow[t]{2}{*}{ PgtSSR68 } & 5 & B & B & B & A, B, C, D & PgtSSR68F: AACCAGGGAACCAAAGGTCT \\
\hline & & & & & . & PgtSSR68R: GATTGACTCGGCAGTTGGAG \\
\hline \multirow{2}{*}{ PgtSSR162 } & 2 & B & B & B & A & PgtSSR162F: TGGACTGGCTTGAACTTGTG \\
\hline & & & & & & PgtSSR162R: ATTCGCGCTCGTCTCGTT \\
\hline \multirow[t]{2}{*}{ PgtCAA53 } & 5 & $\mathrm{C}$ & $\mathrm{C}$ & $\mathrm{C}$ & A, B & PgtCAA53F1: AGGCTCAACACCACCCATAC \\
\hline & $\ldots$ & $\ldots$ & & 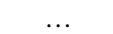 & $\ldots$ & PgtCAA53R1: AGGAGGAGGTGAAGGGGATA \\
\hline \multirow[t]{2}{*}{ PgtCAA93 } & 4 & B & B & B & A, C, D & PgtCAA93F: ATTCGGATGGTCCGTTACTG \\
\hline & & & & & & PgtCAA93R: CGCCTGTGATGGTTGTATTG \\
\hline \multirow{2}{*}{ PgtCAA98 } & 5 & A & A & A & $\mathrm{B}, \mathrm{C}, \mathrm{D}$ & PgtCAA98F1: ATTCGGATGGTCCGTTACTG \\
\hline & $\ldots$ & $\ldots$ & $\ldots$ & $\ldots$ & $\ldots$ & PgtCAA98R1: CCATCCCACTCAAATCATCC \\
\hline
\end{tabular}

y SSR markers: PgtSSR3, PgtSSR4, PgtSSR6, PgtSSR11, PgtSSR12, PgtSSR14, PgtSSR20, PgtSSR47, PgtSSR68, and PgtSSR162 (9); PgtCAA53, PgtCAA93, and PgtCAA98 (this study).

${ }^{z}$ North American isolates. 
isolates produced a near-immune reaction (IT 0 to 0;) on line W2691SrTt-1 and other supplemental differential lines carrying resistance gene $S r 36$, which is typical of race TTKSK (5). These isolates produced an IT 2 on lines LcSr24Ag (carrying Sr24) and Siouxland (carrying Sr24+Sr31), ITs 2 to $2+$ on Triumph 64 (carrying resistance gene $\operatorname{SrTmp}$ ), and ITs 3 to 4 on all other differential lines.

Three isolates (07KEN11-1, 07KEN18, and 07KEN25) produced ITs similar to that of the check isolate 06KEN19v3 and were identified as race TTKST (Table 1). These isolates produced ITs similar to those produced by isolates of race TTKSK except for high ITs on LcSr24Ag (Sr24) and Siouxland (carrying Sr24+Sr31). These isolates represent the variant with virulence on $\mathrm{Sr} 24$ that was first detected in 2006 in Kenya (3). These isolates produced a near-immune reaction (IT 0 to 0 ;) on the supplemental differential lines carrying resistance gene $\mathrm{Sr} 36$ that is typical of race TTKST (3).

Ten isolates derived from six samples produced ITs 3+ to 4 on line W2691SrTt-1 (monogenic for Sr36) and were identified as race TTTSK (Table 1). All isolates of race TTTSK produced high ITs on the supplemental lines carrying $\mathrm{Sr} 36$ but low ITs on lines LcSr24Ag (carrying $\mathrm{Sr} 24$ ) and Siouxland (carrying Sr24 and Sr31) (Table 1). The most diagnostic line for race TTTSK was Sisson (carrying Sr31 and $S r 36$ ), because other races that may pos- sess virulence to $\operatorname{Sr} 36$ would be avirulent on Sisson due to the presence of Sr31. This group of isolates represents a new variant within the TTKS lineage.

Considering the typical low ITs known for TTKS isolates (5), slight variation was observed for $S r 21$ and SrTmp in the TTTSK group (Table 1). Some isolates of race TTTSK produced slightly lower ITs $(2+3$ to $3-)$ on Cns_T_mono_deriv (a monogenic line for $\mathrm{Sr} 21$ in Chinese Spring background) compared with isolates of races TTKSK and TTKST but the ITs were sufficiently high to be considered virulent to $S r 21$. Several isolates of race TTTSK produced slightly higher ITs on CnsSrTmp (a monogenic line for SrTmp in Chinese Spring background) compared with the ITs produced by isolates of races TTKSK and TTKST. However, when tested on Triumph 64, the ITs of race TTTSK appeared to be similar to those produced by races TTKSK and TTKST. Thus, we concluded that race TTTSK was avirulent to SrTmp.

Thirteen SSR markers (Table 2) were used to examine the genetic relationship of 12 isolates of the TTKS race cluster, including the reference isolate 98UGA1-1. In addition, five standard North American isolates were included in the analysis. All 13 SSR markers were polymorphic, with a range of two to five alleles per marker. All 12 isolates of the TTKS race cluster (TTKSK, TTKST, and TTTSK) had an identical SSR genotype and were distinct from the five North American isolates.

Table 3. Infection types (ITs) produced by representative isolates of races in the TTKS lineage of Puccinia graminis f. sp. tritici on selected wheat cultivars postulated to possess resistance gene $S r 36^{\mathrm{y}}$

\begin{tabular}{lcccc}
\hline Line & Market class & $\begin{array}{c}\text { 04KEN156/04 } \\
\text { (TTKSK) }\end{array}$ & $\begin{array}{c}\text { 06KEN19v3 } \\
\text { (TTKST) }\end{array}$ & $\begin{array}{c}\text { 07KEN24-1 } \\
\text { (TTTSK) }\end{array}$ \\
\hline Coker 9663 & Soft red winter & 0 & $0 ;$ & $3+$ \\
Ernie & Soft red winter & 0 & 0 & 4 \\
Japee & Soft red winter & 0 & 0 & 4 \\
NC Neuse & Soft red winter & $0 ; 1 / 2^{\mathrm{z}}$ & $0 ; / 2$ & 4 \\
P91193 & Soft red winter & 0 & 0 & $3+$ \\
Rosen & Soft red winter & 0 & $0 ;$ & $3+$ \\
Sawyer & Soft red winter & 0 & 0 & $3+$ \\
Sisson & Soft red winter & 0 & 0 & 4 \\
SS550 & Soft red winter & 0 & 0 & 4 \\
USG 3209 & Soft red winter & $0 ;$ & $; 1-$ & 4 \\
Roughrider & Hard red winter & 0 & $0 ;$ & 3 \\
Vista & Hard red winter & 0 & 0 & 3 \\
Fireball & Hard red spring & 0 & 0 & $3-$ \\
\hline
\end{tabular}

${ }^{\mathrm{y}}$ ITs at the seedling stage following the descriptions of Stakman et al. (8), where IT $0, ;, 1,2$ or combinations thereof were considered low infection types, IT 3 to 4 were considered high infection types, and + and - were used to denote deviations from the defined type.

${ }^{\mathrm{z}}$ Test entry was heterogeneous, predominant type given first.

Only one SSR marker, PgtSSR68, showed a common allelic genotype between the two North American isolates (70NE286-2 and 76MN1391) and the TTKS lineage. These results confirm the avirulence and virulence phenotype data, indicating that the collections of the TTKS race cluster from Kenya in 2004, 2006, and 2007 are of the same genetic lineage as the original collection (98UGA1-1) made in Uganda in 1998.

Selected wheat cultivars of soft red winter, hard red winter, and hard red spring wheat that were postulated to carry $\operatorname{Sr} 36$ $(4,10$; Y. Jin, unpublished $)$ were tested against the three races of the TTKS lineage (Table 3 ). With a few exceptions where ITs $; 1-$ to $; 1$ were observed, cultivars exhibited ITs of 0 or 0 ; to races TTKSK and TTKST. All cultivars had a high IT to race TTTSK. Among the breeding lines in the 2007 U.S. soft red winter wheat regional nurseries tested against races TTKSK and TTTSK, a large portion of the resistance to TTKSK was conditioned by $S r 36$, because $50 \%$ or more of the TTKSK-resistant lines were susceptible to race TTTSK (Table 4).

The discovery of virulence to $\mathrm{Sr} 36$ within the TTKS lineage, in addition to the previously described virulence to Sr24 (3), demonstrated that the potential for new virulence to occur when a population of $P$. graminis f. sp. tritici is large. Because wheat stem rust is present in Kenya throughout the year, significant quantities of inoculum are always present. This increases the likelihood of developing races with new virulence. The variants found in 2006 and 2007 with virulence to $\operatorname{Sr} 24$ and Sr36 in the TTKS lineage are globally significant because resistance to TTKSK in many adapted cultivars is conferred by these genes. It is anticipated that additional new variants in the TTKS lineage will develop; thus, monitoring of virulence in the $P$. graminis f. sp. tritici population in Kenya is needed for early detection of new races that could attack sources of resistance that are currently effective. In addition, the frequently encountered vulnerability of monogenic resistance to stem rust requires dedicated breeding for durable resistance in wheat.

\section{ACKNOWLEDGMENTS}

We thank L. Wanchura, S. Gale, and K. P. Nguyen for their technical assistance.

Table 4. Resistance to races TTKSK and TTTSK of Puccinia graminis f. sp. tritici of the 2007 U.S. soft red winter wheat regional nurseries

\begin{tabular}{lcccc}
\hline & & \multicolumn{3}{c}{ No. of lines resistance to race } \\
\cline { 3 - 5 } Soft red winter wheat nursery & No. of entries & TTKSK & TTTSK & Sr36 resistance (\%) $^{\mathbf{z}}$ \\
\hline UESRWWN (Uniform Eastern Soft Red Winter) & 45 & 11 & 5 & 54.5 \\
USSRWWN (Uniform Southern Soft Red Winter) & 42 & 19 & 8 & 57.9 \\
GAWN (Gulf-Atlantic Soft Winter) & 82 & 18 & 5 & 72.2 \\
MXD (Mason Dixon Soft Winter) & 60 & 22 & 11 & 50.0 \\
SUN-Pre (Southern University Preliminary) & 148 & 39 & 17 & 56.4 \\
\hline
\end{tabular}

${ }^{\mathrm{z}}$ Resistance to TTKSK due to $\operatorname{Sr} 36$. 
LITERATURE CITED

1. Allard, R. W., and Shands, R. G. 1954. Inheritance of resistance to stem rust and powdery mildew in cytologically stable spring wheats derived from Triticum timopheevi. Phytopathology 44:266-274.

2. Anikster, Y., Szabo, L. J., Eilam, T., Manisterski, J., Koike, S. T., and Bushnell, W. R. 2004. Morphology, life cycle biology and DNA sequence analysis of rust fungi on garlic and chives from California. Phytopathology 94:569-577.

3. Jin, Y., Pretorius, Z. A., Singh, R. P., and Fetch, T., Jr. 2008. Detection of virulence to resistance gene $\mathrm{Sr} 24$ within race TTKS of Puccinia graminis f. sp. tritici. Plant Dis. 92:923-926.
4. Jin, Y., and Singh, R. 2006. Resistance to recent eastern African stem rust isolates with virulence to $\mathrm{Sr} 31$ in US wheat. Plant Dis. 90:476-480.

5. Jin, Y., Singh, R. P., Ward, R. W., Wanyera, R., Kinyua, M. G., Njau, P., Fetch, T., Jr., Pretorius, Z. A., and Yahyaoui, A. 2007. Characterization of seedling infection types and adult plant infection responses of monogenic $\mathrm{Sr}$ gene lines to race TTKS of Puccinia graminis f. sp. tritici. Plant Dis. 91:1096-1099.

6. Roelfs, A. P., Long, D. L., and Roberts, J. J. 1993. Races of Puccinia graminis in the United States during 1990. Plant Dis. 77:125128.

7. Roelfs, A. P., and Martens, J. W. 1988. An international system of nomenclature for $P u c$ cinia graminis f. sp. tritici. Phytopathology 78:526-533.

8. Stakman, E. C., Stewart, D. M., and Loegering, W. Q. 1962. Identification of Physiologic Races of Puccinia graminis var. tritici. U. S. Dep. Agric. Agric. Res. Serv. E-617.

9. Szabo, L. J. 2007. Development of simple sequence repeat markers for the plant pathogenic rust fungus, Puccinia graminis. Mol. Ecol. Notes 7:92-94.

10. Tsilo, T. J., Jin, Y., and Anderson, J. A. 2008 Diagnostic microsatellite markers for detection of stem rust resistance gene Sr36 in diverse genetic backgrounds of wheat. Crop Sci. 48:253-261. 